\title{
Localization of Epidermal Growth Factor Receptor Enhancer Protein in A431 Epidermoid Carcinoma Cells by Southwestern Histochemistry
}

\author{
Ko Komuta ${ }^{1}$, Takashi Kanematsu ${ }^{1}$, Paul K. Nakane ${ }^{2}$ and Takehiko Koji ${ }^{2}$ \\ 'Department of Surgery II and 'Department of Histology and Cell Biology, Nagasaki University School of Medicine, \\ 1-12-4, Sakamoto, Nagasaki 852-8501
}

Received for publication October 23, 1997

\begin{abstract}
Since abnormal expression of epidermal growth factor receptor (EGFR) is frequently associated with cancer development, the analysis of EGFR gene expression at the transcriptional level as well as the transcript level is helpful to understand the abnormal nature of cancer growth. In this study, we attempted to localize EGFR transcriptional factors, EGFR specific transcription factor (ETF) and GC factor (GCF), in the frozen sections of A431 human epidermoid tumor transplated into nude mice by southwestern histochemistry. As probes for southwestern histochemistry, $(+)$ and $(-)$ sequences of the DNA seqment (91 base pairs (bp)) including ETF and GCF regulatory element were synthesized, allowed to be annealed and then tailed by terminal deoxynucleotidyl transferase with digoxigenin (Dig)-11-dUTP. The sites of Dig were visualized enzymeimmunohistochemically with horseradish peroxidase-labeled anti-Dig. The 91 bp probe detected effectively a single ETF band with a molecular mass of $120 \mathrm{kD}$ on a south-

western blot of the crude nuclear fraction extracted from A431 tumor cells, but not a GCF band. When the frozen sections of A431 tumor were fixed with $4 \%$ paraformaldehyde and reacted with the 91 bp probe, the staining of perinuclear area as well as nuclei in a speckled pattern were observed and the staining intensity was increased depending upon the concentrations of the probe and reached a plateu level at 0.5 $1 \mu \mathrm{g} / \mathrm{ml}$. Moreover, the nuclear staining with the probe was dependent upon a salt concentration and the signal/noise ratio was a maximam at $150 \mathrm{mM} \mathrm{NaCl}$. The staining with the 91 bp probe was abolished by the presence of an excess amount of unlabeled 91 bp DNA or unlabeled ETF responsive element DNA alone, but not by that of unlabeled GCF DNA, indicating that the nuclear and perinuclear staining with the 91 bp probe reflects the localization of ETF. Thus, southwestern histochemistry can be a novel tool to analyze cellular expression of genespecific transcription regulatory factors.
\end{abstract}

Key words: Epidermal growth factor receptor, ETF, Southwestern histochemistry, A431

\section{Introduction}

The epidemal growth factor receptor (EGFR) gene has been found to be amplified and/or expressed at high levels in various types of tumor cells including A431 human epidermoid carcinoma cells $[12,13,16]$. Although the over-production of EGFR protein generally correlates with an elevated level of its mRNA, it does not always accompany EGFR gene amplification $[4,18]$. Therefore, to understand better the mechanism of abnormal expression

Correspondence to: Dr Ko Komuta ${ }^{1}$ and Dr. Takehiko Koji2 ${ }^{1}$ Department of Surgery II and ${ }^{2}$ Department of Histology and Cell Biology, Nagasaki University School of Medicine, 1-12-4, Sakamoto, Nagasaki 852-8501, Japan. of the gene, cellular analysis of transcriptional factors trans-acting on EGFR gene is required.

Recently, Kageyama et al. have found that EGFR transcription factor (ETF) specifically stimulates EGFR gene transcription $[2,3]$ and that GC factor (GCF) conversely represses the transcription of the gene [1]. Thereafter, biochemical analyses on a mass of cells or tissues were conducted to clarify the expression of these transcription factors and their roles in the regulation of EGFR gene expression. However, cellular understanding of the expression of the transcription factors was only poor, because of lack of appropriate antibodies. Very recently, we have developed a method to localize specific DNA binding proteins using haptenized double-stranded (ds) DNAs containing specific consensus base sequences [6-8, 
10]. The method, named southwestern histochemistry, may enable us to analyze the expression of transcription regulatory factors as specific DNA binding proteins at individual cell level $[6,10]$.

In this study, as the first step to clarify the relationship between EGFR gene expression and their trans-acting transcriptional factors, ETF and GCF, we attempted to localize the transcription factors by southwestern histochemistry in the fresh frozen sections of A431 human epidermoid tumors, using digoxigenin (Dig) labeled ds oligonucleotides as probes. As a result, we obtained specific signals for ETF successfully with a modified protocol, and they were localized to the perinuclear regions as well as the nuclei in a speckled pattern in A431 tumor cells.

\section{Materials and Methods}

\section{Cells and tissues}

A431 human epidermoid carcinoma cells were obtained from the Japanese Cancer Research Resources Bank (JCRB)-Cell. The cell line was maintained in RPMI 1640 cuture medium supplemented with $10 \%$ FCS, penicillin $(100 \mathrm{IU} / \mathrm{ml})$, streptomycin $(100 \mathrm{mg} / \mathrm{ml})$, and glutamine $(0.2 \mathrm{mg} / \mathrm{ml})$ at $37^{\circ} \mathrm{C}$ in a $5 \% \mathrm{CO}_{2}$ atmosphere.

To produce A431 tumors, about $1 \times 10^{6}$ cells in $0.2 \mathrm{ml}$ of Hanks' balanced salt solution were implanted s.c. in the male athymic BALB/c nude mice ( 8 weeks old). Four weeks later, the mice were killed and tumors exceeding $5 \mathrm{~mm}$ in diameter were resected. They were embedded in OCT compound (Miles Inc., IN, USA) and quickly frozen in ethanol/dry ice.

\section{Oligodeoxynucleotide (Oligo-DNA)}

We synthesized three sets of oligo-DNAs on an automated DNA synthesizer (Applied Biosystems, Model 391 PCR-Mate). The first set (ETF oligo-DNA) of $(+)$ and $(-)$ oligo-DNAs consisted of ETF responsive element [3] which located at the nucleotide no. -204 to $-214,-233$ to -248 , and -282 to -292 in the EGFR promoter region. The second set (GCF oligo-DNA) oligo-DNAs was corresponding to the DNA segment of EGFR promoter, nucleotide no. -225 to -243 and -263 to -278 , which was recognized as GCF reponsive element [1]. The third set (91 base pair (bp) oligo-DNA) was corresponding to the entire 91 bp regulatory region of EGFR (nucleotide no. -201 to -292), including both ETF and GCF responsive elements. These synthesized oligo-DNAs were purified by an OPC column and were labeled at 3 '-end with Dig-11-dUTP by terminal deoxynucleotidyl transferase [5].

\section{Polyacrylamide gel electrophoresis (PAGE) analysis of annealed ds oligo-DNA}

The $(+)$ and $(-)$ strands of each synthesized oligoDNAs were mixed, denatured and annealed with different protocols; 1) boiling for $5 \mathrm{~min}$ and incubation at (Tm-25) ${ }^{\circ} \mathrm{C}$ i.e., $75.5^{\circ} \mathrm{C}$ (in the case of the $91 \mathrm{bp}$ oligo DNA) for
$30 \mathrm{~min}, 2$ ) boiling for $5 \mathrm{~min}$, cooling at $4^{\circ} \mathrm{C}$ for $10 \mathrm{~min}$ and incubation at (Tm-25) ${ }^{\circ} \mathrm{C}$ for $30 \mathrm{~min}, 3$ ) boiling for $5 \mathrm{~min}$, cooling at $4^{\circ} \mathrm{C}$ for $10 \mathrm{~min}$ and incubation at room temperature (RT) for $30 \mathrm{~min}$ and 4) incubation at $(\mathrm{Tm}-25){ }^{\circ} \mathrm{C}$ for $5 \mathrm{~min}$ and at RT for further $30 \mathrm{~min}$. Then the oligoDNAs were separated by PAGE with 4-20\% gradient gel and were stained with the silver staining kit (Daiichi Pure Chem. Co., Japan).

\section{Southwestern blot analysis of nuclear extract from A431 epidermoid tumors}

The nuclear extract of A431 tumors was prepared according to Wildman et al. [17] and separated by SDSPAGE with 4-20\% gradient gel without boiling the samples. Three slabs of the separated proteins were electrophoretically transferred onto nylon membranes according to the user manual of immunoblotting system (Daiichi Pure Chem. Co., Japan), and one of them was stained with the silver staining for visualization of protein bands. The molecular weight markers were as follows; bovine skeletal muscle myoglobin (17.2 kD), bovine erythrocyte carbonic anhydrase $(30 \mathrm{kD})$, rabbit skeletal muscle aldolase $(42.4 \mathrm{kD})$, bovine serum albumin $(66.3 \mathrm{kD})$, E. coli $\beta$-galactosidase (116.2 kD) and rabbit skeletal muscle myosin myosin $(200 \mathrm{kD})$.

The blotted nylon membrane was processed according to Silva et al. [14] with a slight modification. Briefly, the blot was incubated with a preincubation solution containing $5 \%$ non-fat dry milk dissolved in $10 \mathrm{mM}$ Tris/ $\mathrm{HCl}$ (pH 7.4) buffer containing $50 \mathrm{mM} \mathrm{NaCl}$ and $1 \mathrm{mM}$ EDTA for overnight at $4^{\circ} \mathrm{C}$. Then the blot was reacted with $1 \mu \mathrm{g} / \mathrm{ml}$ Dig-labeled ds oligo-DNA dissolved in the preincubation solution for $3 \mathrm{hr}$ at RT. After successive washings with the preincubation solution (twice, $1 \mathrm{hr}$ each) and PBS (3 times, $1 \mathrm{hr}$ each), the blot was incubated for $1 \mathrm{hr}$ in a blocking solution that contained 5\% BSA and $500 \mu \mathrm{g} / \mathrm{ml}$ normal sheep IgG in PBS. The reaction with HRP-linked sheep anti-Dig IgG (Fab), which was diluted at $1: 800$ with the blocking solution, was performed for $1 \mathrm{hr}$. As a chromogen solution of HRP, a mixture of DAB, $\mathrm{H}_{2} \mathrm{O}_{2}$, cobalt chloride and nickel ammonium sulfate was used [9].

To confirm the sequence specificity in the reaction of labeled ds oligo-DNA probes with the blotted proteins, the blot was reacted with $1 \mu \mathrm{g} / \mathrm{ml}$ probe in the presence of an excess amount (100-450-fold) of the unlabeled ds oligoDNA.

\section{Southwestern histochemistry}

The frozen sections $(5 \mu \mathrm{m})$ were cut, placed onto 3aminopropyltriethoxysilane coated glass slides and were air dried. The sections were fixed in $4 \%$ paraformaldehyde in PBS for $30 \mathrm{~min}$ at RT. After several washes with PBS, the sections were immersed in the preincubation buffer for $1 \mathrm{hr}$. Then the sections were incubated overnight with the labeled ds oligo-DNAs dissolved in the preincubation buffer ( $5 \%$ non-fat dry milk dissolved in $10 \mathrm{mM}$ Tris $/ \mathrm{HCl}(\mathrm{pH} 7.4)$ buffer containing $150 \mathrm{mM} \mathrm{NaCl}$ 
and $1 \mathrm{mM}$ EDTA) at a concentration of $0.25,0.5,1$, or $2 \mu \mathrm{g} / \mathrm{ml}$. In some trials, the concentration of $\mathrm{NaCl}$ in the reaction mixture was varied ranging from 50 to $200 \mathrm{mM}$. The sites of Dig-ds oligo-DNA reacted with the sections were visualized, as described in Southwestern blotting. To verify the sequence specificity of the signals, some tissue sections were reacted with $0.5 \mu \mathrm{g} / \mathrm{ml}$ of Dig-ds oligo-DNA probe in the presence of an excess amount (100-fold) of the corresponding unlabeled ds oligoDNA. Moreover, some sections were digested with RNase A $\left(100 \mu \mathrm{g} / \mathrm{ml}, 37^{\circ} \mathrm{C}, 1 \mathrm{hr}\right)$ before immersing in the preincubation buffer.

\section{Results}

\section{Optimization of annealing conditions of oligo-DNA}

To ensure the specific interaction between a transcription factor and its regulatory element DNA sequences, the

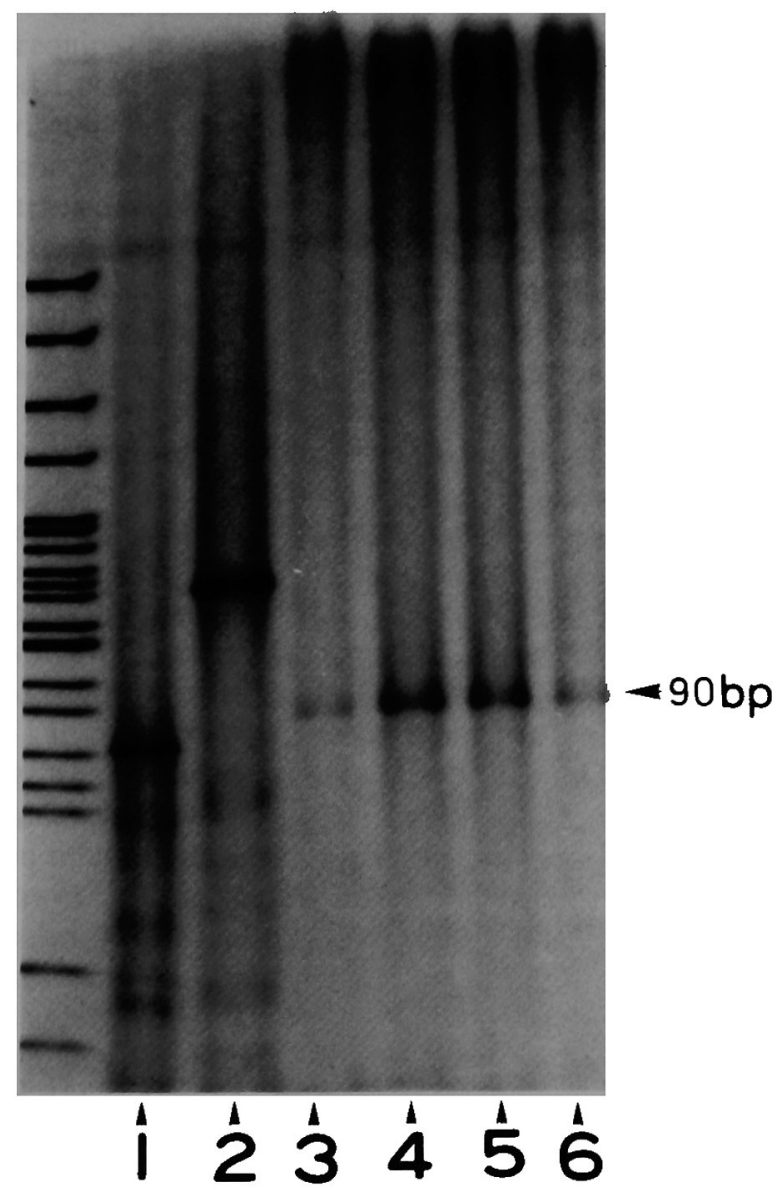

Fig. 1. Gel-electrophoretic analysis of ds probe DNA prepared by different denaturation and annealing protocols. (+) (lane 1) and (-) (lane2) strands of the 91 bp DNA segment and ds probe DNAs prepared by boiling for $5 \mathrm{~min}$ and incubation at $75.5^{\circ} \mathrm{C}$ for $30 \mathrm{~min}$ (lane 3), boiling for $5 \mathrm{~min}$, cooling at $4^{\circ} \mathrm{C}$ for $10 \mathrm{~min}$ and incubation at $75.5^{\circ} \mathrm{C}$ for $30 \mathrm{~min}$ (lane 4), boiling for $5 \mathrm{~min}$, cooling at $4^{\circ} \mathrm{C}$ for $10 \mathrm{~min}$ and incubation at RT for $30 \mathrm{~min}$ (lane 5), and incubation at $75.5^{\circ} \mathrm{C}$ for $5 \mathrm{~min}$ and at RT for $30 \mathrm{~min}$ (lane 6). probe DNA should be double-stranded. Therefore, first of all, we tried to optimize the denaturation and annealing protocol of synthetic oligo-DNAs. As shown in Fig. 1, single-stranded (+) and (-) strands of the 91 bp oligoDNA moved to different positions on SDS-PAGE, probably due to a difference in the tertiary structures. Among diffferent protocols, the most intense $91 \mathrm{bp}$ band was obtained with the protocol secondary and/or consisting of boiling for $5 \mathrm{~min}$, cooling at $4^{\circ} \mathrm{C}$ for $10 \mathrm{~min}$ and incubation at (Tm-25) ${ }^{\circ} \mathrm{C}$ (i.e., $75.5^{\circ} \mathrm{C}$ in this case) for $30 \mathrm{~min}$. In the following experiments, we used the conditions to anneal oligo-DNAs to be double stranded.

\section{Southwestern blot analysis of the nuclear extract from A431 human epidermoid tumors with 91 bp oligo-DNA probe}

In order to evaluate the reactivity and specificity of the 91 bp oligo-DNA probe with ETF or GCF, we carried out southwestern blot analysis of the nuclear exract from A431 tumors. The probe used here was the $91 \mathrm{bp}$ Dig-ds oligo-DNA, which contained 3 ETF elements and 2 GCF

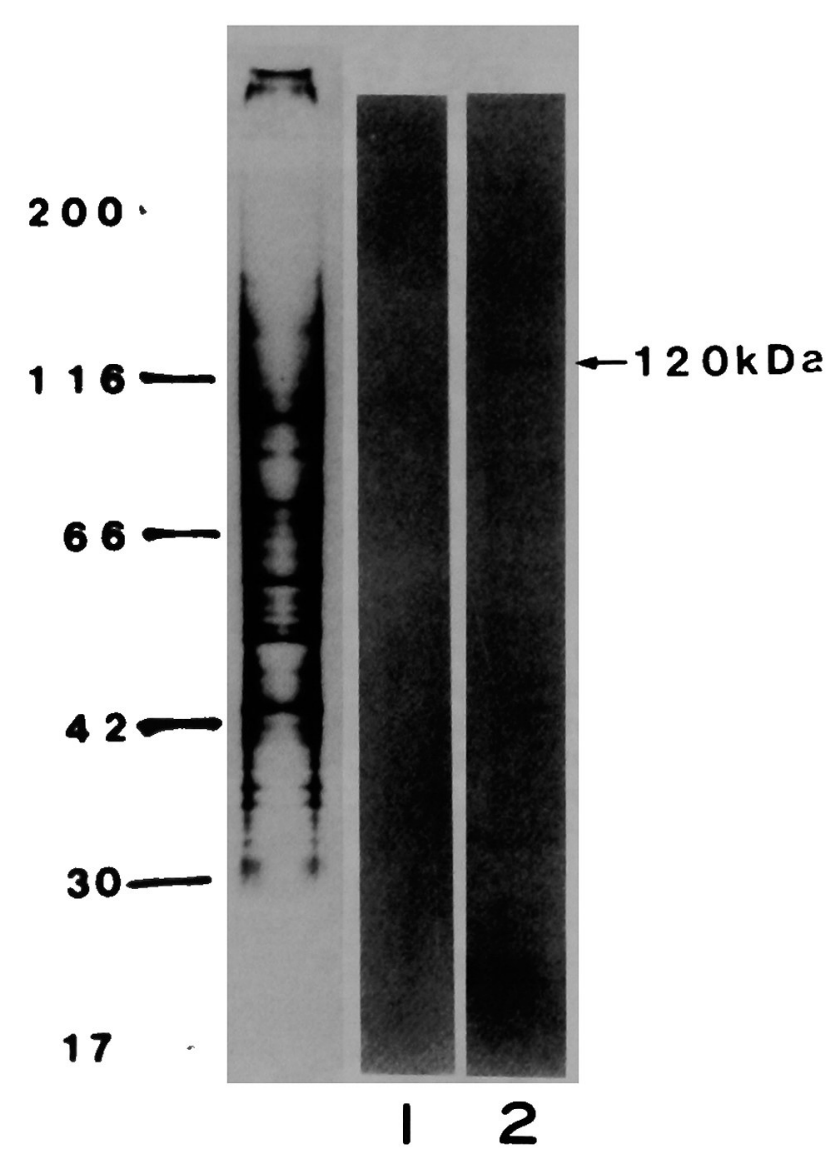

Fig. 2. Southwestern blotting of the nuclear extract from A431 tumors. The nuclear extract from A431 tumors was separated on a SDS-PAGE and transferred onto a nylon membrane, which was reacted with Dig-91 bp ds oligo-DNA in the presence (lane 1) or absence (lane 2) of an exess amount (450-fold) of unlabeled $91 \mathrm{bp}$ ds oligo-DNA. Left lane; molecular weight marker. 


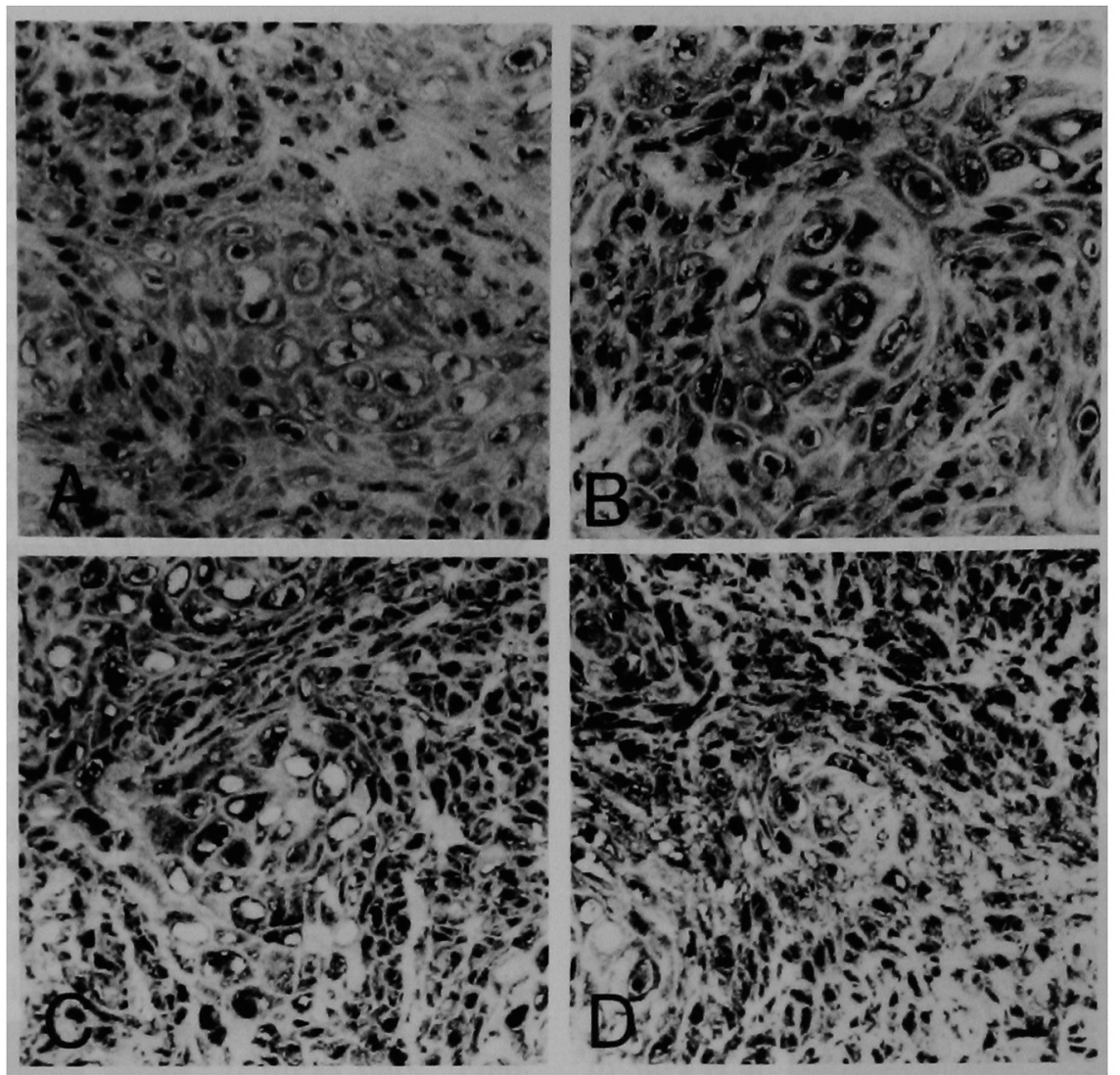

Fig. 3

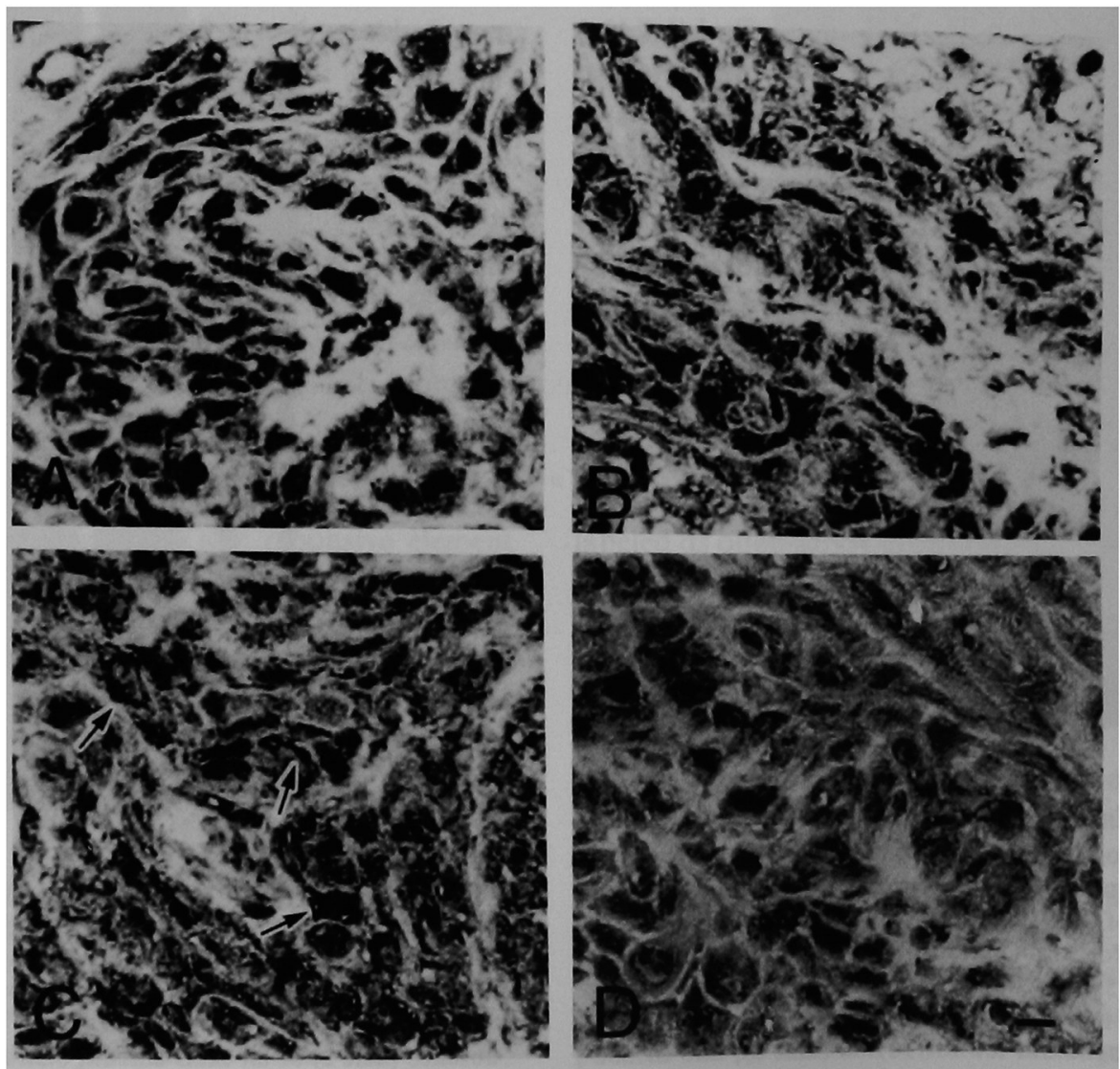

Fig. 4 
elements. As shown in Fig. 2, a single band with molecular weight of $120 \mathrm{kD}$ was detected. Based upon its molecular weight, the band was regarded as that of ETF, as reported previously [3]. When the blot was reacted with the $91 \mathrm{bp}$ ds oligo-DNA probe in the presence of an excess amount of unlabeled ETF ds oligo-DNA, the band was completely abolished (Fig. 2). On the other hand, no band around $90 \mathrm{kD}$ corresponding to GCF was found with the 91 bp probe.

\section{Localization of ETF in frozen sections of A431 tumors by southwestern histochemistry}

Using the $91 \mathrm{bp}$ dsoligo-DNA probe, we attempted to localize the transcription factors of EGFR gene in the frozen sections of A431 tumors. When the sections were reacted with the $91 \mathrm{bp}$ probe at various concentrations, the nuclei as well as the perinuclear regions were positive and the staining intensity was increased by increasing the probe concentration, reaching a plateu level at $0.5-1.0 \mu \mathrm{g} / \mathrm{ml}$ (Fig. 3).

It is known that an appropriate concentration of salt is required to keep the specific interaction between protein and DNA. Also, DNA binding proteins including transcription factors such as steroid hormone receptors and cyclic AMP responsive element binding proteins are extracted with a high-salt concentration buffer [15]. Then we examined the effect of increasing concentrations of $\mathrm{NaCl}$ in the reaction mixture upon the nuclear and perinuclear staining with the $91 \mathrm{bp}$ ds oligo-DNA probe. As shown in Fig. 4, at a low concentration of $\mathrm{NaCl}$, e.g. $50 \mathrm{mM}$, the nuclei were completely covered with choromogen deposits and considering that transcriptional machineries distribute in a speckled pattern at least some parts of the staining could be regarded as nonspecific. At a $\mathrm{NaCl}$ concentration of $150 \mathrm{mM}$, very clear localization of the signals in the perinuclear regions as well as in the nuclei in a speckled manner was obtained. However, the staining was suddenly lost at the higher concentration of $\mathrm{NaCl}$.

In order to verify the specificity of the nuclear staining, we conducted various control expriments. When the Dig-labeled 91bp oligo-DNA was omitted from the reaction mixture, no nuclear staining was observed (data not shown). Also, when a section was reacted with the Diglabeled $91 \mathrm{bp}$ ds oligo-DNA probe in the presence of an excess amount of unlabeled 91 bp ds oligo-DNA (Fig. 5B) or unlabeled ETF ds oligo-DNA (Fig. 5C), the nuclear staining was markedly decreased. However, the staining was not changed by the presence of an exess amount of unlabeled GCF ds oligo-DNA (data not shown). In
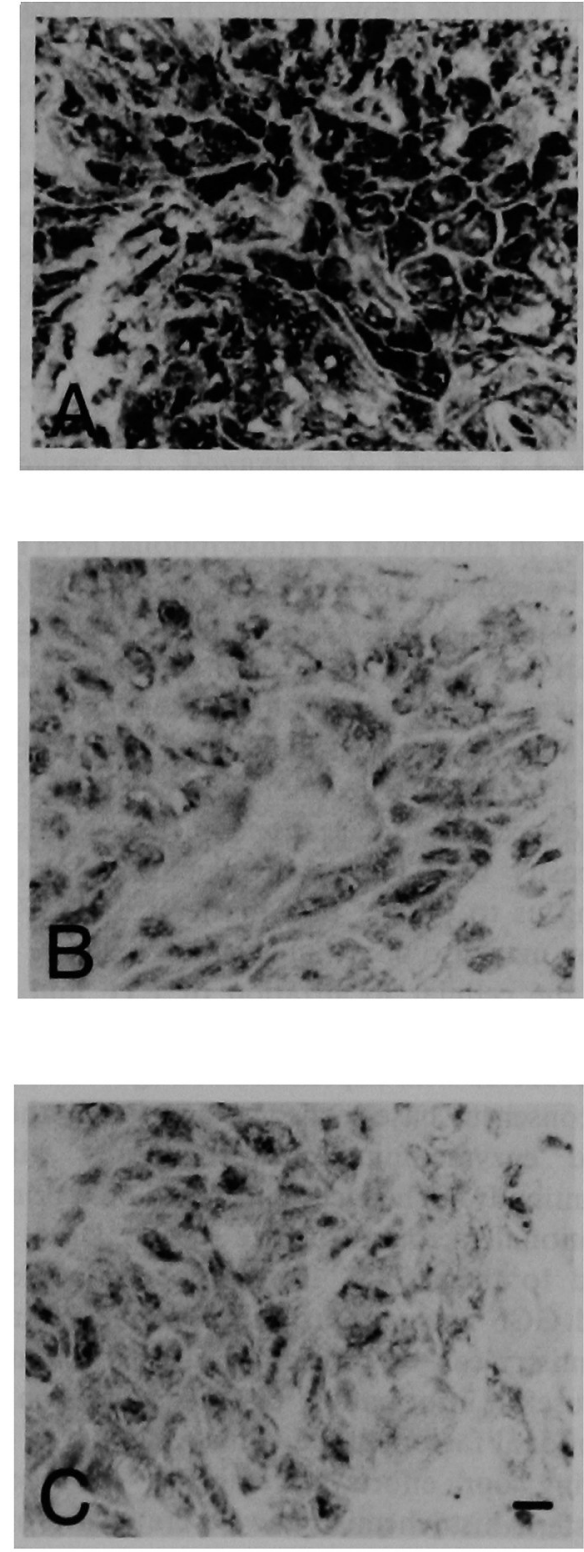

Fig. 5. Specificity of the staining for ETF in the frozen sections of A431 tumor. The frozen sections of A431 tumor were reacted with the Dig-91 bp ds oligo-DNA probe in the presence (B) or absence (A) of an excess amount of unlabeled 91 bp ds oligo-DNA. In (C), the probe was competed with an excess amount of unlabeled ETF ds oligo-DNA. Magnification; $\times 400 \mathrm{Bar}=4 \mu \mathrm{m}$.

Fig. 3. Effect of increasing concentrations of the probe DNA in the reaction mixture on the staining intensity. The frozen sections of $A 431$ tumor were reacted with the Dig-91 bp ds oligo-DNA probe at a concentration of $0.25 \mu \mathrm{g} / \mathrm{ml}(\mathrm{A}), 0.5 \mu \mathrm{g} / \mathrm{ml}(\mathrm{B}), 1.0 \mu \mathrm{g} / \mathrm{ml}(\mathrm{C})$ and $2.0 \mu \mathrm{g} / \mathrm{ml}$
(D). Magnification; $\times 400 \mathrm{Bar}=4 \mu \mathrm{m}$.

Fig. 4. Effect of increasing concentrations of $\mathrm{NaCl}$ in the reaction mixture on the staining. The frozen sections of A431 tumor were reacted with the Dig-91 bp ds oligo-DNA probe at a NaCl concentration of $50 \mathrm{mM}(\mathrm{A}), 100 \mathrm{mM}(\mathrm{B}), 150 \mathrm{mM}$ (C) and $300 \mathrm{mM}$ (D). Magnification;
$\times 400 \mathrm{Bar}=4 \mu \mathrm{m}$. 
accordance with the above results, the ETF Dig-ds oligoDNA probe gave essentially the same staining pattern with the 91bp ds oligo-DNA, while the GCF ds oligo-DNA probe gave only a weak nucleolar staining (data not shown). In addition, when a section was digested with RNase before the reaction with the labeled $91 \mathrm{bp}$ ds oligoDNA, the nuclear staining was not altered, indicating that the nuclear staining was not due to nuclear RNA (data not shown).

\section{Discussion}

For a better understanding of the regulation of gene expression, an analysis at a transcriptional level in individual cells is essential. In the present study, we attempted to examine the expression of transcription regulatory factors of the EGFR gene in human A431 epidermoid carcinoma cells by means of southwestern histochemistry. The lines of trials and errors to optimize experimental conditions required for the new technology finally enabled us to obtain the specific perinuclear and nuclear signals for ETF. The intensity of ETF signals fluctuated among cells, permitting us to predict that the level of EGFR mRNA expression may also be variable among cells.

For the cellular localization of ETF and GCF, we conducted southwestern histochemistry, in which a tissue section is reacted with haptenized ds oligo-DNA harboring specific consensus base sequences and finally the signal is visualized enzyme-immunohistochemically with HRPlabeled antibody. The method is based on a principle that transcriptional factors recognize specific DNA sequences and bind to them $[6-8,10]$. Since antibodies against ETF and GCF are not currently available, southwestern histochemistry can be considered as only one method to offer a useful information on the expression of these transcriptional factors in individual cells.

During our efforts to improve the protocol of southwestern histochemistry, we were aware of the fact that a complete annealing of $(+)$ and $(-)$ strands of probe DNA is essential for reproducible and intense signals and the best protocol. Also, we found that the best signal/ noise ratio was obtained at $150 \mathrm{mM} \mathrm{NaCl}$ in the reaction mixture; at the lower concentration of $\mathrm{NaCl}$, we encountered a high background staining, and at the higher concetration, an abrupt loss in the staining happened.

The EGFR gene is the cellular homolog of the v-erbB oncogene. In various tumors, over-expression of EGFR protein is well known [11-13, 16], and it has often been a main subject for analysis of the mechanism underlying the abnomal nature of their cell growth $[4,18]$. Although in some cases amplification of EGFR gene [12] was the cause of the elevated level of EGFR expression, the over-expression of EGFR without its gene amplification was also reported $[4,18]$. In A431 cells, which reveal an extremely high level of EGFR gene expression, the rearrangement as well as amplification of the EGFR gene have been observed and both alterations have been proposed as possible causes of over-expression of EGFR gene [4, 18]. In this study, we raised a possibility of involvement of other factor in the over-expression of EGFR gene, namely an elevated level of ETF expression.

Actually, we could not detect a GCF band in the southwestern blot with the $91 \mathrm{bp}$ ds oligo-DNA probe, even though the probe sequences contained the GCF responsive element at two sites. Consistent with the blotting result, the staining with the $91 \mathrm{bp}$ ds oligo-DNA probe in the frozen sections of the A431 tumor was mostly abolished by the competition with unlabled ETF ds oligoDNA, but not unlabeled GCF ds oligo-DNA. Considering that GCF was originally discovered in A431 cells, our failure to find the GCF signals with the $91 \mathrm{bp}$ ds oligo-DNA probe may reflect that the number of GCF is only less than our detection sensitivity. Alternatively, the tertiary structure of the $91 \mathrm{bp}$ ds oligo-DNA may hide the GCF responsive element sites not to be reactive with the GCF protein. In this context, it should be noted that with the Dig-labeled GCF ds oligo-DNA probe, a faint, but reproducible staining of nucleoli was found in the frozen sections of the A431 tumor. Anyway, for more convincing detection of GCF our protocol will have to be further improved in the future.

Finally, we succeeded to localize ETF, an enhancer protein of EGFR gene, in the frozen sections of A431 tumor and the signals were found in the perinuclear region as well as the nucleus in a speckled fashion. The research to correlate the ETF expression with the degree of EGFR mRNA expression at the level of individual cells is now in progress in our laboratory, by using southwestern histochemistry and in situ hybridization [6,11]. By combining these methods, a much more precise understanding of the states of gene expression will be obtained in individual cells.

\section{References}

1. Kageyama, R. and Pastan, I.: Molecular cloning and chracterization of a human DNA biding factor that represses transcription. Cell 59; 815-825, 1989.

2. Kageyama, R., Merlino, G. T. and Pastan, I.: A transcription factor active on the epidermal growth factor receptor gene. Proc. Natl. Acad. Sci. USA 85; 5016-5020, 1988.

3. Kageyama, R., Merlino, G. T. and Pastan, I.: Nuclear factor ETF specifically stimulates transcription from promoters without a TATA box. J. Biol. Chem. 264; 15508-15514, 1989.

4. King, C. R., Kraus, M. H., Willoams, L. T., Merlinl, G. T., Pastan, I. H. and Anderson, S. A.: Human tumor cell lines with EGF receptor gene amplification in the absence of aberrant sized mRNAs. Nucleic Acids Res. 13; 8477-8486, 1985.

5. Koji, T. and Brenner, R. M.: Localization of estrogen receptor messenger ribonucleic acid in rhesusmonkey uterus by nonradioactive in situ hybridization with digoxigenine-labeled oligodeoxynucleotides. Endocrinology 132; 382-392, 1993.

6. Koji, T. and Nakane P.K.: Recent advances in molecular histochemical techniques: in situ hybridization and southwestern histochemistry. J. Electron Microsc. 45; 119-127, 1996.

7. Koji, T., Yamada, S., Izumi, S. and Nakane, P. K.: Oligo- 
histochemistry: a new approach to localize DNA biding proteins. J. Histochem. Cytochem. 38; 1052, 1990.

8. Koji, T., Yamada, S., Kayashima, K. and Nakane, P. K.: A new approach to localize glucocorticoid receptor using DNA probe containing glucocorticoid responsive element DNA consensus sequences. Acta Histochem. Cytochem. 25; 681-687, 1992.

9. Koji, T., Izumi, S., Tanno, M., Moriuchi, T. and Nakane, P. K.: Localization in situ of c-myc mRNA and c-myc protein in adult mouse testis. Histochem. J. 20; 551-558, 1988.

10. Koji, T., Komuta, K., Nozawa, M., Yamada, S. and Nakane, P. K.: Localization of cyclic adenosine 3,5-monophosphateresponsive element (CRE) binding protein by In situ southwestern histochemistry. J. Histochem. Cytochem. 42; 1399-1405, 1994.

11. Komuta, K., Koji, T., Izumi, S., Matsumoto, T., Kohara, N., Motojima, K., Kanematsu, T. and Nakane, P. K.: Expression of epidermal growth factor receptor messenger RNA in human colorectal carcinomas assessed by nonradioactive in situ hybridization. Eur. J. Surg. Onc. 21; 269-275, 1995.

12. Lin, C. R., Chen, W. S., Kruiger, W., Stolarsky, L. S., Wdber, W., Evans, R. M., Verma, I. M., Gill, G. N. and Rosenfeld, M. G.: Expression cloning of human EGF receptor complementary DNA: gene amplification and three related messenger RNA products in A431 cells. Science 224; 843-848, 1984.

13. Merlino, G. T., Xu, Y. -H., Ishii, S., Clark, A. J. L., Semba, K., Toyoshima, K., Yamamoto, T. and Pastan, I.: Amplifica- tion and enhanced expression of the epidermql growth factor recptor gene in A431 human carcinoma cells. Science 224; 417 $419,1984$.

14. Silva, C. M., Tully, D. B., Petch, L. A., Jewell, C. M. and Cidlowski, J. A.: Application of protein-blotting procedure to the study of human glucocorticoid receptor interactions with DNA. Proc. Natl. Acad. Sci. USA 84; 1744-1749, 1987.

15. Slyden, O. D., Koji, T. and Brenner, R. M.: Microwave stabilization enhances imunocytochemical detection of estrogen receptor in frozen sections of macaque oviduct. Endocrinology 136; 4012-4021, 1995.

16. Ullrich, A., Coussens, L., Hayflick, J. S., Dull, T. J., Gray, A., Tam, A. W., Lee, J., Yarden, Y., Libermann, T. A., Schlessinger, J., Downward, J., Mayes, E. L. V., Whittle, N., Waterfield, M. D. and Seeburg, P. H.: Human epidermal growth factor receptor cDNA sequence and aberrant expression of the amplified gene in A431 epidermoid carcinoma cells. Nature 309; 418-425, 1984.

17. Wildeman, A. G., Sassone-corsi, P., Grundstroem, T., Zenke, M. and Chambon, P.: Stimulation of in virto transcription from the SV40 early promoter by the enhancer involves a specific trans-acting factor. $E M B O J .3 ; 3129-3133,1984$.

18. Xu, Y. -H., Richert, N., Ito, S., Merlino, G. T. and Pastan, I.: Characterization of epidermal growth factor receptor gene expression in malignan and normal human cell lines. Proc. Natl. Acad. Sci. USA 81; 7308-7312, 1984. 